


Social



\title{
EFFECTS OF ASANA PRACTICES AND STRETCHING EXERCISES COMBINED WITH NEUROMUSCULAR DRILLS ON CARDIO RESPIRATORY ENDURANCE OF SCHOOL GIRLS
}

\author{
Dr. D. Maniazhagu ${ }^{* 1}$, Soniya James ${ }^{2}$, S. Malar ${ }^{3}$ \\ ${ }^{* 1}$ Assistant Professor, Department of Physical Education and Health Sciences, Alagappa \\ University, Karaikudi \\ ${ }^{2}$ M.Phil Scholar, Department of Physical Education and Health sciences, Alagappa University, \\ Karaikudi \\ ${ }^{3}$ Ph.D Scholar (Full Time), Department of Physical Education and Health Sciences, Alagappa \\ University, Karaikudi
}

\begin{abstract}
The aim of present study was to find out the effects of asana practices and stretching exercises combined with neuromuscular drills on cardio respiratory endurance of school girls. Thirty school girls with the age group of 12-14 years from Holly Cross Convent School, Nedumkandam, Idukki, Kerala, were randomly selected. They were assigned into three equal groups, two experimental and one control group. The experimental group-1 ( $\mathrm{n}=10$, AP-NMD) and group-2 ( $\mathrm{n}=10$, SE-NMD) received asana practice combined with neuromuscular drills and stretching exercise combined with neuromuscular drills respectively for the period of six weeks, three days per week. Cardio respiratory endurance was measured by 9 minutes run/walk test and scores recorded in meters. The data was collected pre and posttest training intervention. The ANCOVA was used to find out the overall significant differences among the group. The Scheffe's Post Hoc test was used to find out pair- wise comparisons between groups. After six weeks, $0.46 \%$ and $0.34 \%$ of increase in the capacity of cardio respiratory endurance was observed in the asana practice combined with neuromuscular drills and stretching exercise combined with neuromuscular drills respectively. The capacity of cardio respiratory endurance was highly developed in asana practice combined with neuromuscular drills than the stretching exercise combined with neuromuscular drills and control group.
\end{abstract}

Keywords: Cardio Respiratory Endurance; Asana; Stretching Exercise; Neuromuscular Drills; ANCOVA.

Cite This Article: Dr. D. Maniazhagu, Soniya James, and S. Malar. (2018). "EFFECTS OF ASANA PRACTICES AND STRETCHING EXERCISES COMBINED WITH NEUROMUSCULAR DRILLS ON CARDIO RESPIRATORY ENDURANCE OF SCHOOL GIRLS." International Journal of Research - Granthaalayah, 6(10), 221-226. https://doi.org/10.29121/granthaalayah.v6.i10.2018.1188. 


\section{Introduction}

The term yoga comes from the words Sanskrit word 'yuj' which means to joint yoke together to unify and to unite as one yoga has existed from the ancient times but was integrated and simplified by patanjali in the fifth A.D century. With the help of yogic exercises we will increase the flexibility or elasticity of our body and make the body more active and supple. The greater the concentration will be the greater the advantage to the body and mind. Increase the practice body will become more and more elastic and flexible day by day. (Joshi, 1991) Stretching, as it relates to physical health and fitness, is the process of placing particular parts of the body into a position that will lengthen the muscles and their associated soft tissues. Upon undertaking a regular stretching programme a number of changes begin to occur within the body and specifically within the muscles themselves. Other tissues that begin to adapt to the stretching process include the fascia, tendons, skin and scar tissue. (Brad Walker, 2011) Cardio respiratory endurance is the single most important component of health related physical fitness. The exception occurs among older adults, for whom muscular strength is particularly important. In any case, people can get by without a good cardio respiratory system, facilitated by aerobic exercise (Hoeger, 2017).

\section{Materials and Methods}

The study was formulated as pre and post test random group design, in which thirty subject were randomly assigned into three equal groups. During training, the experimental groups underwent their respective training as per schedule given below. Control group maintained normal activities.

\section{Statistical Analysis}

The collected pre and post data was critically analyzed with apt statistical tool of analysis of covariance (ANCOVA), for observed the significant adjusted post-test mean difference of three groups. The Scheffe's post hoc test was used to find out pair-wise comparisons between groups. To test the hypothesis 0.05 level of significant was fixed in this study.

\section{Training Approaches}

Training approaches for experimental group 1-(AP-NMD) Asana Practices

\begin{tabular}{|c|c|c|c|c|}
\hline \multicolumn{2}{|l|}{ Activities } & \multirow{4}{*}{$\frac{\text { Duration }}{3 \mathrm{~min}}$} & \multirow{4}{*}{\begin{tabular}{|l} 
Sets \\
2
\end{tabular}} & \multirow{4}{*}{\begin{tabular}{|l|} 
Recovery in between set \\
$2 \mathrm{~min}$
\end{tabular}} \\
\hline \multirow[t]{3}{*}{ Suryanamaskar (12steps) } & $1-2$ weeks & & & \\
\hline & 2-3 weeks & & & \\
\hline & veeks & & & \\
\hline \multirow{3}{*}{$\begin{array}{l}\text { Asanas } \\
\text { (Pachimottasana, Vajrasana, } \\
\text { Danurasana, Navasana, } \\
\text { Bhujangasana, Vipareethakarani) }\end{array}$} & $1-2$ weeks & $15 \mathrm{sec}$ & 3 & $3 \min$ \\
\hline & 2-3 weeks & $30 \mathrm{sec}$ & 3 & $3 \min$ \\
\hline & 5-6 weeks & $45 \mathrm{sec}$ & 3 & $3 \min$ \\
\hline
\end{tabular}

\section{Neuromuscular drills}

The subjects were performed ladder exercises for neuromuscular drills. 
A ladder consists of 20 boxes; the subjects performed the following exercises,

1) Vertical jump for first 10 boxes and run for the next 10 boxes.

2) High knee for first 10 boxes and run for next 10 boxes.

3) Back kick for first 10 boxes and run for next 10 boxes.

\begin{tabular}{|l|l|l|l|l|}
\hline \multicolumn{2}{|l|}{ Ladder Drills } & Repetition & Sets & Recovery in between set \\
\hline $\begin{array}{l}\text { Vertical jump and run } \\
\text { High knee and run } \\
\text { Back kick and run }\end{array}$ & $\mathbf{1 - 2}$ weeks & 5 & 3 & 2 min \\
\cline { 2 - 5 } & 3-4 weeks & 5 & 4 & 2 min \\
\cline { 2 - 5 } & 5-6 weeks & 5 & 5 & 2 min \\
\hline
\end{tabular}

Training Approaches for Experimental Group 2-(SE-NMD) Stretching Exercise

\begin{tabular}{|l|l|l|l|}
\hline Activities & Duration & Sets & Recovery in between set \\
\hline Stretching Exercises & \multicolumn{2}{|l|}{$\mathbf{1 - 2}$ weeks } \\
\cline { 2 - 3 } $\begin{array}{l}\text { Flexion and extension } \\
\text { Cross arm in front of cheat }\end{array}$ & $15 \mathrm{sec}$ & 3 & $3 \mathrm{~min}$ \\
Forward lunge(fencer) & $\mathbf{3 - 4}$ weeks \\
\cline { 2 - 3 } $\begin{array}{l}\text { Supine knee flex } \\
\text { Side bend with straight arms } \\
\text { Semi straddle }\end{array}$ & $30 \mathrm{sec}$ & 3 & $3 \mathrm{~min}$ \\
Straddle (spread eagle) & \multicolumn{3}{|l|}{} \\
\cline { 2 - 4 } Butterfly & $\mathbf{5 - 6}$ weeks \\
\cline { 2 - 3 } & $45 \mathrm{sec}$ & 3 & $3 \mathrm{~min}$ \\
\hline
\end{tabular}

\section{Neuromuscular Drills}

The subjects were performed ladder exercises for neuromuscular drills.

A ladder consists of 20 boxes; the subjects performed the following exercises,

1) Vertical jump for first 10 boxes and run for the next 10 boxes.

2) High knee for first 10 boxes and run for next 10 boxes.

3) Back kick for first 10 boxes and run for next 10 boxes.

\begin{tabular}{|l|l|l|l|l|}
\hline \multicolumn{2}{|l|}{ Ladder Drills } & Repetition & sets & Recovery in between set \\
\hline Vertical jump and run & $\mathbf{1 - 2}$ weeks & 3 & 3 & 2 min \\
\cline { 2 - 5 } High knee and run & $\mathbf{3 - 4}$ weeks & 4 & 3 & $2 \mathrm{~min}$ \\
\cline { 2 - 5 } Back kick and run & $\mathbf{5 - 6}$ weeks & 5 & 3 & $2 \mathrm{~min}$ \\
\hline
\end{tabular}

\section{Results and Discussions}

Table I: The Results of Analysis of Covariance on Cardiorespiratory Endurance of Different Groups (Scores in meters)

\begin{tabular}{|l|l|l|l|l|l|l|l|l|l|}
\hline \multicolumn{2}{|l}{ Test Conditions } & $\begin{array}{c}\text { Group 1 } \\
\text { AP-NMD }\end{array}$ & $\begin{array}{c}\text { Group 2 } \\
\text { SE-NMD }\end{array}$ & $\begin{array}{c}\text { Group 3 } \\
\text { CG }\end{array}$ & SV & SS & Df & MS & 'F' Ratio \\
\hline \multirow{2}{*}{ Pre test } & Mean & 1410.00 & 1417.50 & 1420.00 & B & 541.67 & 2 & 270.83 & 1.01 \\
\cline { 2 - 9 } & S.D. & 7.75 & 18.06 & 18.44 & W & 7262.50 & 27 & 286.98 & \\
\hline
\end{tabular}




\begin{tabular}{|l|l|l|l|l|l|l|l|l|l|}
\hline Post test & Mean & 1456.00 & 1451.50 & 1421.50 & $\mathrm{~B}$ & 7035.00 & 2 & 3517.50 & $18.83^{*}$ \\
\cline { 2 - 8 } & S.D. & 14.28 & 2.29 & 17.18 & $\mathrm{~W}$ & 5045.00 & 27 & 186.85 & \\
\hline $\begin{array}{l}\text { Adjusted } \\
\text { post test }\end{array}$ & Mean & 1458.46 & 1450.80 & 1419.74 & $\mathrm{~B}$ & 8018.57 & 2 & 4009.28 & $27.77^{*}$ \\
\cline { 5 - 8 } & & & & $\mathrm{W}$ & 3753.58 & 26 & 144.37 & \\
\hline
\end{tabular}

* Significant at .05 level of confidence. The required table value for test the significance was 3.35, and 3.37, with the df of 2 and 27,2 and 26.

\section{Results of Cardio Respiratory Endurance}

The pre test mean and standard deviation on cardio respiratory endurance scores G1, G2, and G3 were $1410.00 \pm 7.75,1417.50 \pm 18.06$, and $1420.00 \pm 18.44$, respectively. The obtained pre test $\mathrm{F}$ value of 1.01 was lesser than the required table $F$ value 3.35 . Hence the pre test means value of asana practice combined with neuromuscular drills and stretching exercise combined with neuromuscular drills and control group on cardio respiratory endurance before start of the respective treatments were found to be insignificant at 0.05 level of confidence for the degrees of freedom 2 and 27. Thus this analysis confirmed that the random assignment of subjects into three groups were successful.

The post test mean and standard deviation on cardio respiratory endurance scores G1, G2, and G3 were $1456.00 \pm 14.28,1451.50 \pm 2.29$ and $1421.50 \pm 17.18$ respectively. The obtained post test $\mathrm{F}$ value of 18.83 was greater than the required table $F$ value of 3.35 Hence the post test means value of asana practice combined with neuromuscular drills and stretching exercise combined with neuromuscular drills on cardio respiratory endurance were found to be significant at 0.05 level of confidence for the degrees of freedom 2 and 27. The results proved that asana practice combined with neuromuscular drills and stretching exercise combined with neuromuscular drills were produced significant improve rather than the control group of the sample populations.

The adjusted post test means on cardio respiratory endurance scores of G1, G2 and G3 were $1458.46,1450.80$ and 1419.74 respectively. The obtained adjusted post test $F$ value of 27.77 was higher than the required table $\mathrm{F}$ value of 3.37. Hence the adjusted post test means value of asana practice combined with neuromuscular drills and stretching exercise combined with neuromuscular drills on cardio respiratory endurance were found to be significant at 0.05 level of confidence for the degrees of freedom 2 and 26. The results confirmed that asana practice combined with neuromuscular drills and stretching exercise combined with neuromuscular drills on cardio respiratory endurance were produced significant difference among the groups.

In order to find out the superiority effects among the treatment and control groups the Scheffe's post hoc test were administered. The outcomes of the same are presented in the table I (a).

Table -I (a): Scheffe's Post Hoc Test Mean Differences on Cardiorespiratory Endurance Among Three Groups (Scores in meters)

\begin{tabular}{|l|l|l|l|l|}
\hline $\begin{array}{l}\text { Group 1 } \\
\text { AP-NMD }\end{array}$ & $\begin{array}{l}\text { Group 2 } \\
\text { SE-NMD }\end{array}$ & $\begin{array}{l}\text { Group 3 } \\
\text { C G }\end{array}$ & Mean Differences & Confidence Interval Value \\
\hline 1458.46 & 1450.80 & & $7.66^{*}$ & 3.12 \\
\hline 1458.46 & & 1419.74 & $38.72^{*}$ & 3.12 \\
\hline & 1450.80 & 1419.74 & $31.05^{*}$ & 3.12 \\
\hline
\end{tabular}

* Significant at .05 level of confidence. 


\section{Result of Scheffe's post hoc test on cardio respiratory endurance}

Table I (a) shows the paired mean differences of asana practice combined with neuromuscular drills, stretching exercise combined with neuromuscular drills and control group on cardio respiratory endurance. The paired wise comparisons results as follows.

First comparison: Group 1 and Group 2: The pair wise mean difference of group 1 and group 2 values 7.66 was higher than the confidential interval value of 3.12. Hence the first comparison was significant. The results of this comparison clearly proved that both training have produced different improvements on cardio respiratory endurance.

Second comparison: Group 1 and Group 3 The pair wise mean difference of group 1 and group 3 values 38.72 was higher than the confidential interval value of 3.12 . Hence the second comparison was significant. The results of this comparison clearly proved that asana practice combined with neuromuscular drills have produced greater improvements on cardio respiratory endurance than the control group.

Third comparison: Group 2 and Group 3 The pair wise mean difference of group 2 and group 3 values 31.05 was higher than the confidential interval value of 3.12. Hence the third comparison was significant. The results of this comparison clearly proved that stretching exercise combined with neuromuscular drills have produced greater improvements on cardio respiratory endurance than the control group.

The adjusted post test mean deference of experimental and control group value graphically represented in the figure 1 .

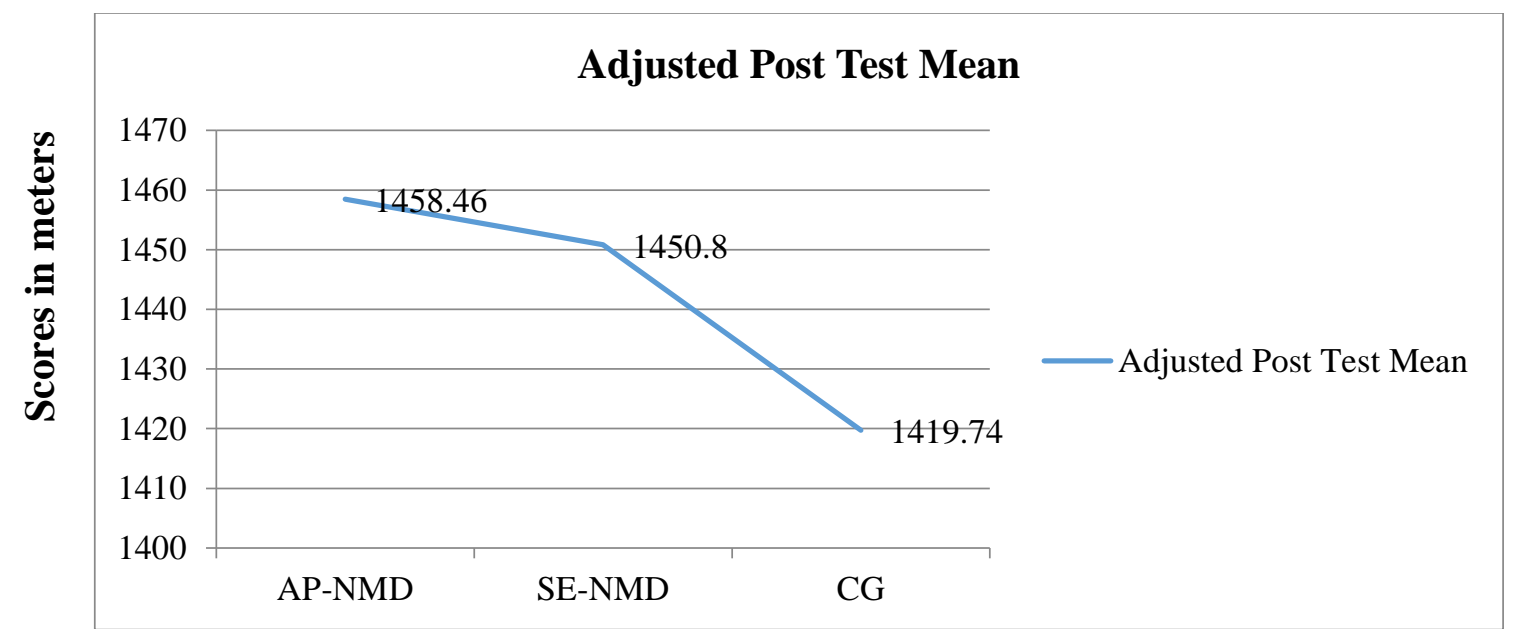

Figure 1: The adjusted post test mean values of experimental and control groups on cardio respiratory endurance

\section{Discussion on Findings}

The results of the present study were demonstrated positive effect on the Cardio respiratory endurance. This results of the present study in line with the following studies. The findings of the study in effects of a 12-week hatha yoga intervention on cardio respiratory endurance, muscular strength and endurance, and flexibility in Hong Kong Chinese adults: a controlled clinical trial showed that the 12-week Hatha yoga intervention has favourable effects on cardio respiratory endurance, muscular strength and endurance, and flexibility (Caren Lau, Ruby Yu, and Jean Woo, 
2015). The study, effects of yogic practices on selected cardio respiratory endurance of men students demonstrated that the yogic practices produced significant improvement on cardio respiratory endurance. (Vinu, 2015). The effects of yoga conditioning for athletes on cardio respiratory endurance demonstrated that there was a significant improvement on cardio respiratory endurance due to yoga conditioning. (April Woody, 2008) The research findings from the effects of exercise training on Cardio respiratory fitness and biomarkers of cardio metabolic health: A systematic review and meta-analysis of randomized controlled trials showed that the exercise significantly improved cardio respiratory fitness and some cardio metabolic biomarkers. (Xiaochen Lin, et.al. 2014)

\section{Conclusion}

The capacity of cardio respiratory endurance was highly improved in asana practice combined with neuromuscular drills than the stretching exercise combined with neuromuscular drills and control group.

Further the stretching exercise combined with neuromuscular drills produced better improvement than the control group on cardio respiratory endurance.

The control group did not show any significant improvement on cardio respiratory endurance.

\section{References}

[1] April Woody (2008). "The Effects of Yoga Conditioning for Athletes on Cardiorespiratory Endurance”. Cantaurus, Vol. 16, 28-31, May 2008 (C) McPherson College Division of Science and Technology

[2] Brad Walker, 2011, "Ultimate guide to stretching and flexibility". P.No; 9

[3] Caren Lau, Ruby Yu, and Jean Woo (2015). "Effects of a 12-Week Hatha Yoga Intervention on Cardio respiratory Endurance, Muscular Strength and Endurance, and Flexibility in Hong Kong Chinese Adults: A Controlled Clinical Trial". Evidence-Based Complementary and Alternative Medicine, Volume 2015, Article ID 958727, 12 pages, http://dx.doi.org/10.1155/2015/958727

[4] Joshi K.S, "Yoga and nature care therapy" "sterling publisher private limited"1991

[5] Vinu (2015). "Effects of yogic practices on selected cardio respiratory endurance". International Journal of physical education, sports and Health. Vol1 Issue 6 Part B. P.No: 109-111.

[6] Wener W.K. Hoeger, Sharon A. Hoeger (2017), "Lifetime Physical Fitness and Wellness: A Personalized Program" P.No. 206

[7] Xiaochen Lin, Xi Zhang, Jianjun Guo, Christian K Roberts, Steve McKenzie, Wen-Chih Wu, Simin Liu and Yiqing Song (2014). "Effects of Exercise Training on Cardio respiratory Fitness and Biomarkers of Cardio metabolic Health: A Systematic Review and Meta-Analysis of Randomized Controlled Trials" J Am Heart Assoc. 2015 Jul; 4(7): e002014. Published online 2015 Jun 25. doi: 10.1161/JAHA.115.002014

\footnotetext{
*Corresponding author.

E-mail address: drmaniazhagu@ gmail.com
} 